\title{
Artístico e Contextual, o lugar reinventado - reflexões sobre a relação antigo-novo a partir de Francisco De Gracia e Giovanni Carbonara
}

\author{
Fabiola do Valle Zonno
}

Professora do Departamento de História e Teoria da Faculdade de Arquitetura e Urbanismo da Universidade Federal do Rio de Janeiro (FAU-UFRJ), e do Programa de Pós-Graduação em Arquitetura (PROARQ-UFRJ)

Contato: fabiolazonno@fau.ufrj.br

\section{RESUMO}

O trabalho contribui para o reconhecimento do estado da arte sobre o tema da relação entre a nova arquitetura e a pré-existência de valor patrimonial, apresentando de modo analítico os pontos de vista de dois expoentes autores no debate internacional: Francisco de Gracia (1992 e 2013) e Giovanni Carbonara (2011), cujas obras não foram ainda traduzidas para o português. As possibilidades de intervenção apontadas pelos teóricos são criticamente aproximadas à perspectiva da própria autora (2014 e 2016), no sentido de reconhecer diferentes modos de interpretar a obra arquitetônica como artística na sua relação com o contexto, posto como problema o sentido de lugar como reinvenção - entre a permanência e a produção.

Palavras-chave: intervenção, patrimônio, arquitetura contemporânea.

\section{ABSTRACT}

The essay contributes to the recognition of the state of the art on the subject of the relation between the new architecture and the pre-existence of patrimonial value, presenting in an analytical way the points of view of two outstanding authors in the international debate: Francisco de Gracia (1992 and 2013) and Giovanni Carbonara (2011), whose works have not yet been translated into Portuguese. The possibilities of intervention pointed out by theorists are critically approximated to the perspective of the author (2014 and 2016), in the way of recognizing different ways of interpreting the architectonic work as artistic in its relation with the context, presenting as a problem the sense of place as a reinvention - between permanence and production.

Key-words: intervention, heritage, contemporary architecture. 


\section{De onde falamos: Artístico e Contextual}

A possibilidade de a arquitetura ser tratada como ação artística e contextual já foi estudada por nós pensando o lugar como reinvençáo de uma situação específica no contexto da paisagem contemporânea em sua complexidade. Em nosso trabalho "Lugares complexos, poéticas da complexidade - entre arte, arquitetura e paisagem" ${ }^{1}$ (ZONNO, 2014), procuramos não só compreender a relação entre arte $\mathrm{e}$ arquitetura nas poéticas contemporâneas - a partir das obras, processos e escritas de artistas e arquitetos - buscando conexóes com a arte pop, arte minimalista e pós-minimalista e conceitual, bem como reconhecer modos outros de entender, via site specificity, o contextual e a produção de lugar na contemporaneidade. O lugar pode ser pensado de modo complexo, "lugar complexo", explorando sua condição de atualidade a evocar e produzir novos significados, sempre como interpretação do existente - o contextual como diálogo que constitui produção de sentido - não só de modo consonante, mas também de modo paradoxal, ambíguo ou conflituoso - como valor artístico ${ }^{2}$ específico a uma situação, capaz de reinventar a paisagem.

Com Ignasi Solà-Morales (apud ZONNO, 2014, p.98), o "lugar" não é apenas o que afirma um sentido de "permanência", mas também de "produção" - uma "fundação conjuntural" a partir das energias atuais. Acompanhamos Fábio Duarte (2009, p.99), ao reconhecer o lugar como "porção de espaço significada" a partir de processos de ressignificação constantes, e que "é preciso levar em conta a complexidade da cultura contemporânea para discuti-lo, sem o saudosismo de um lugar perdido". Conectando o tema da criação de lugar como ação "contextual" às discussóes no campo da arte site specific, reconhece- mos com Miwon Kwon (apud ZONNO, p.39) as suas múltiplas possibilidades de abordagem, entre os quais destacamos aspectos tanto fenomenológicos como discursivos, o que nos levou a pensar as operaçôes contextuais em termos também conceituais e potencialmente críticos.

Aproximando estas reflexóes às de Bernard Tschumi (2004 e 2012) sobre arquitetura e conceito, compreendemos o contexto não como um "dado", mas como parte de uma problemática engendrada pelo arquiteto em sua interpretação sobre um sítio específico, para o qual reconhece significados e valores e afirmamos a criação da arquitetura como criação do pensamento, entrelaçado às questóes levantadas, em que se assume um posicionamento ou modo poético (dentre muitos possíveis).

Partindo destas bases em que afirmamos a possibilidade da relação contextual como artística, nossa pesquisa $^{3}$ atual tem como enfoque o tema da memória e, em especial, a problemática do projeto de intervenção, como adição arquitetônica, relacionado a pré-existências de valor patrimonial: o "antigo-novo". É claro que há situaçôes bastante distintas com as quais se defronta o arquiteto, que variam segundo os "graus" de reconhecimento prévio dos valores históricos e artísticos dos bens e sítios como patrimônio e como participam, hoje, de uma paisagem que possui traços próprios, mais ou menos heterogêneos também como palimpsesto do tempo.

A partir de nosso olhar, o tema é entendido como uma investigação sobre as possibilidades da arquitetura nova, como arte site specific e modo poético de aproximação ao antigo, reinventar o "lugar", interpretando seus valores a partir do olhar do presente 
(construção de memória), buscando expor significados e criar significados. A "liberdade" artística advém de uma abordagem poética que parte e se entrelaça ao existente como condição mesma de sua própria significação.

\section{Compreendemos o conjunto antigo-novo como}

lugar reinventado quando o antigo é interpretado e o projeto contemporâneo é capaz de instaurar de modo poético novas possibilidades de fruição e significação. A intervenção contemporânea em um contexto de valor patrimonial deve ser reconhecida como ação criativa, como obra de arte, a partir de diferentes possíveis modos de relação com a pré-existência, com a paisagem.

É neste sentido que para tratar a discussão sobre o "artístico" em intervenções antigo-novo, devemos somar as questóes próprias à teoria e à crítica da arquitetura contemporânea e a compreensão das poéticas dos artistas/arquitetos às questôes próprias ao campo do patrimônio, para que se possa, de fato, contribuir ao debate para além de visóes reducionistas ou demasiado restritivas sobre as possibilidades de intervenção.

Nossa abordagem parte do princípio, com Roberto Pane (apud Kühl, 2008, p.161), de que se existe uma realidade de estratificação histórica que se consolidou ao longo do tempo, o presente tem o direito de se afirmar historicamente desde que "a nova arquitetura seja subordinada à análise do ambiente como uma obra coletiva", "como parte integrante de um "tecido historicizado". Ou seja, todos os tecidos urbanos passaram por alteraçóes no tempo e considerá-los como “intocáveis" seria aliená-los da relação com o presente, seria o contrário da concepção de cultura como processo vivo.

O autor Ignasi Solà-Morales é referencial para nos- so trabalho tanto por sua abordagem à arquitetura contemporânea (Diferencias de 2003 e Territorios de 2002), bem como sobre sua visão sobre o conceito de "intervenção como interpretação" (Intervenciones de 2006) no patrimônio.

Neste artigo, temos como objetivo apresentar e analisar, de modo interpretativo e crítico, o pensamento de dois importantes autores que tratam do tema do antigo-novo, respectivamente na Espanha e na Itália - Francisco De Gracia ${ }^{4}(1992$ e 2013) e Giovanni Carbonara5 (2011) - buscando identificar seus modos de entender a relação entre arquitetura e contexto e como os identificam a questóes estéticas. De Gracia, pensando o "construir no construído", possui um determinado entendimento sobre o que define "arquitetura contextual" e Carbonara, coloca a possibilidade de uma "terceira via" entre uma arquitetura historicista e uma arquitetura high tech e atópica.

\section{O antigo-novo entre a crítica do historicismo e da autoexpressáo}

Os significados dos lugares inevitavelmente se transformam; posicionamentos polarizados podem nos conduzir seja, como diz Rem Koolhaas (1995) à "nostalgia do passado" ou à "nostalgia do futuro". Neste sentido, é preciso situar os riscos da permanência como nostalgia: a museificação de nossas paisagens e a compreensão da identidade como mitificação, pois o permanente só o é por meio de uma memória vivida.

Sobre a "musealização", Solà-Morales (2003) fala de um efeito "parque temático": monumentos e ruínas em um processo de "exposição que fatalmente produzirá sua desaparição como objetos ligados a situa- 
çôes e significados concretos" - um estado de "arquiteturas áureas" voltadas ao turismo de massa. Constata que a situação, apontada por Guy Debord, de espetacularizaçáo ligada ao universo da mercadoria e do jogo de "espelhos" que caracteriza o mundo das imagens, leva também a espaços "simulados" como lugares históricos.

De outro extremo, criticam-se as abordagens nostálgicas em relação ao futuro, pois que indiferentes à consideração do passado e à possibilidade da arte construída a partir de uma relação com ele - ideologias não só do novo como novidade, mas muitas vezes como produto de uma visão de cidade pautada pelo consumo.

Carbonara (2011, p.18) dirige uma crítica à arquitetura como "pura atividade artística" sem outro objetivo além da expressão individual ou a celebração publicitária, "escolhas estéticas" como "modos narcisistas de exibição", "globalizados e desastrosos" que não compreendem a paisagem como "transformação contínua, gradual, congruente e necessária”, em seu "processo formativo". Ao falar dos procedimentos resultantes, cita Padella, descrevendo-os como "objetos egocêntricos", "potência da novidade", "tecnologia da admiração" e também cita De Fusco, que fala de uma "arquitetura de conversa vazia", notadamente desconstrutivista, em defesa da "liberdade da fantasia" e da "expressão individual a todo o custo", favorecendo a artisticidade emergente contra a arte mais difusa e razoável”. A partir de Petranzan, Carbonara levanta a questão de a própria "modalidade" antigo-novo ser um novo modismo, em que o bem de valor patrimonial, a pré-existência, é somente um "pre-texto", refletindo a vontade dos arquitetos de se colocarem lado a lado com os arquitetos do passado, muitas vezes sem um "diálogo respeitoso".

Carbonara monta o problema da intervenção antigo- -novo a partir da oposição entre uma arquitetura que retoma os valores de uma modernidade vanguardista e revolucionária, high tech, globalizada, atópica e a-histórica (pela "liberdade" do novo), e de outro, de uma pós-modernidade regressiva, imitativa e falsificante (historicamente regressiva, repristinatória). Em sua visão, deve-se combater o conservadorismo ideológico, mas também a inescrupulosidade consciente.

Esta montagem pode ser nitidamente aproximada à polaridade entre os modos de pensamento historicista e histórico-modernista ${ }^{6}$. Gustavo Rocha Peixoto, acompanhando Solà-Morales, fala de um terceiro, o modo "culturalista", com base na ideia de "cultura arquitetônica" como tradição que se transmite e é compreendida a partir de uma relação nova e atenta com o passado.

Como afirma Solà-Morales em texto de 1999 (2003, p.257), o paradigma tecnológico-psicológico do moderno - "arte como racionalidade técnica de um lado e de outro como expressão dos sentimentos e emoçôes do arquiteto como intérprete dos desejos e esperanças da sociedade" - entra em crise nos anos 1950, quando se colocam questôes da fenomenologia, do humanismo, da antropologia e da história crítica, e a história passa a ocupar um lugar central na fundamentação teórica da arquitetura. Esta visão está presente desde a ideia de um "passado amigo" para Ernesto Nathan Rogers, passando por Colin Rowe e seus estudos com base em uma visão formalista e estruturalista, a Manfredo Tafuri e uma "história crítica” das visóes ideológicas.

$\mathrm{O}$ que entender por cultura arquitetônica, e seus limites com o historicismo, na fala de cada teórico do tema antigo-novo, é uma questão.

Francisco De Gracia (2013) critica a "desculturização" da arquitetura e uma arquitetura de "sobremo- 
dernidade", fruto do afastamento da história como suporte para o pensamento crítico, somado ao fenômeno da cultura mediática e do consumo que, nas últimas décadas, criou imagens arquitetônicas extravagantes distantes do sentido de "construção integrada da forma urbana”. Em sua visão, a arquitetura teria renunciado construir a cidade como "obra de arte", como se reconhecia na cidade tradicional, acentuando a ideia de "identidade formal autônoma":

A ideia de singularidade ou particularidade do objeto prevaleceu sobrequalquer açãointegradora. Seimpôs a colisão formal frente à congruência, já que esta implica em maior esforço na gestão do projeto, assim como assumir o existente e criar amálgamas, o que supóe um conhecimento implícito do passado, algo que modernos e ultramodernos dificilmente podem aceitar. (DE GRACIA, 2013, p.4, tradução da autora)

De Gracia afirma que o maior perigo não é tanto o novo que surge, mas o antigo que desaparece para "fazer eco ao novo". Em sua visão, por maior que seja o apreço que temos pela cidade tradicional, os centros históricos estão submetidos, de modo inevitável, como qualquer outra realidade material, a processos de obsolescência e devemos aceitar a presença de uma "tensão regeneradora" pautada na "renovação morfológica, ainda que limitada", quando então faz-se necessária uma abordagem "metodológica e técnica". Concordamos com o autor com a ideia de necessária renovaçáo morfológica frente a toda museificação artificial da paisagem e que não devemos recair em um "historicismo paralisante e epigônico". Mas a questão que se impóe, a partir da fala de De Gracia são os "limites" ou ainda, o como criar, o que entender por esta perspectiva de um "método", e ainda em uma abordagem "técnica", visto que, na contemporaneidade, reconhecem-se diversos modos de pensar o processo projetual E, além disso, que visão de paisagem reconhecemos como "artística".

Solà-Morales (2003, p.263-266) já afirmava que a história não era mais o paradigma da teoria da arquitetura, magistra vitae e compreende que, a partir de Foucault, as coisas não são mais que o cruzamento de suas relaçóes e que nosso conhecimento sobre elas depende de detectar os fluxos que se entrecruzam em um evento. Se a própria história não busca modelos de explicação total, mas pretende diferentes sentidos a partir de relaçóes transversais, estamos no contexto do pluralismo epistemológico, no qual "parece diluir-se a ideia de que a arquitetura necessite, para sua própria identidade, de paradigmas inquestionáveis como garantia permanente". Somente a "criatividade interpretativa, criticando modelos e noçóes que se tornaram convencionais", permitirá desenvolver um trabalho de análise e compreensão renovados para que se reconheça aquelas proposições que significam um "entendimento rico, agudo e criador de um novo significado da realidade". Acompanhamos e referendamos ainda uma vez o autor:

Não se trata de advogar de um lassez faire ultraliberal, mas do reconhecimento de que não há uma única razão ou método para abordar a proteção, restauração e reutilização. (...). Se algo se pode considerar positivo na situação cultural contemporânea é que ela passou dos sistemas de valores definidos, legitimados, estabelecidos pelos poderes, para uma situaçáo reflexiva na qual o juízo sobre uma experiência, 
uma imagem, uma conduta não é dada de forma pré-determinada, mas exige um processo de elaboração através da confrontação com indivíduos e grupos, através de interpretaçôes. Da parte de quem atua como expert, como artista, como político no chamado Patrimônio Monumental existem sempre riscos a assumir que somente se esclarecem através do debate e confrontação de ideias e opçóes distintas. Em outras palavras, a única coisa possível é fazer proposiçóes que, na medida em que náo tem uma validação prévia, devem ser suficientemente flexíveis, provisórias, abertas para poderem ser alteradas, reconsideradas e modificadas. (SOLÀMORALES, 2003, tradução da autora)

Hoje entendemos a necessidade de ultrapassar a dicotomia "permanência" e "produção" para reconhecer as possibilidades da arquitetura de modo mais transitivo, considerando os debates sobre os limites entre o moderno e o contemporâneo e sobre os modos como a memória participa do processo imaginativo de criação arquitetônica, numa visão em que a "cultura arquitetônica” é campo fértil para a produção poética de cada artista - para além de "métodos" tipológicos. Reconhecer o "lugar", ao mesmo tempo, como "permanência" e como "produção" é pensar a questão antigo-novo como modalidades criativas que reúnam a ambos, passado e futuro em sua transitividade, como fundamentais à nossa visão de cultura no presente.

Não é o uso da tecnologia contemporânea ou de formas expressivas - juízo apriorístico sobre uma arquitetura rotulada como "high tech" ou "desconstrutivista" - que deve ser criticado, mas a possibilidade de reconhecer a nova arquitetura como uma adição que constitua a um só tempo uma ação de preservação do passado e a criação do patrimônio do futuro. Uma atitude em relação à pré-existência e à paisagem urbana onde o novo se insere e se afirma como o que guarda relação com a singularidade da situação, partindo do reconhecimento de seus valores materiais e imateriais e projetando novos valores. Deste modo, pensando o lugar como permanência e produção e a paisagem como interpretação ou reinvenção, a arquitetura contemporânea deve se reconhecer como parte de uma "cultura arquitetônica" (da qual também o moderno faz parte) que guarda múltiplas possibilidades inventivas no trânsito entre a memória e a inovaçáo.

\section{Artístico E? Contextual - posicionamentos sobre o "novo"}

No debate que cerca a relação entre o artístico e o tema das intervençóes antigo-novo nos deparamos muitas vezes com a identificação do "artístico" à afirmação de uma absoluta liberdade criadora a despeito de qualquer preocupação contextual identificada à relação com a estética moderna. Esta visão do "arquiteto artista", "doador de forma”, cujo significado seja apreendido como autorreferente frente ao contexto, seja fruto de expressão centrada na subjetividade do autor ou de uma abordagem racional abstrata - "objeto" isolado do local onde se insere - já foi bastante discutida.

Como ideias que criticaram a visão da obra de arte como "objeto" isolado, destaca-se a vertente dos neorracionalistas nos anos 1960, que retomou a ideia de "cidade como obra de arte" de Camillo Sitte partiu com para métodos de análise de estruturas de linguagem, especialmente no que se refere ao "locus" e 
a aceitação de "tipologias", defendendo articulação entre os elementos novo e antigo como partícipes de uma estrutura da qual dependia a permanência do significado para a memória coletiva.

Rafael Moneo (1978) contribui para a discussão, reconhecendo o valor da interpretação das estruturas formais não só como uma leitura do sítio, mas como possibilidades de o arquiteto, como posicionamento ideológico, aceitar, recusar, transformar ou mesmo produzir novos tipos - criar arquitetura a partir de "articulaçóes sutis" reconhecidas a partir de fragmentos do passado.

Vale destacar também a ideia de cidade por Colin Rowe e Fred Koetter (1975), em que a postura do "bricoleur" é aproximada à arte da "colagem" para engendrar uma "condição de equilíbrio" e de significado entre os fragmentos do passado e os do presente, para sustentar através de dispositivos formais (figura-fundo) relaçóes entre elementos distintos como defesa de uma paisagem da pluralidade - de temporalidades, de regimes, de pensamentos.

Outra vertente se pode reconhecer no pensamento por uma "fenomenologia do lugar" com Norberg Schulz (1976), defendendo um possível reconhecimento do genius loci, "espirito do lugar", a partir da manifestação material como o caráter que o arquiteto deveria ser capaz de identificar como paisagem cultural. Lugar é apresentado como "fenômeno qualitativo": totalidade constituída de coisas concretas que possuem substância material, forma, textura e cor que, juntas, determinam uma "qualidade ambiental" que seria a "essência do lugar", "atmosfera", o como das "coisas mesmas" reconhecível a partir do "espaço vivido".

É a partir deste breve pano de fundo que podemos reconhecer um estado da arte das discussóes sobre o lugar, para compreendermos os posicionamentos sobre o tema das adiçôes arquitetônicas, o "novo", em Francisco De Gracia e Giovanni Carbonara.

\section{1 "Arquitetura contextual" e "técnica de invenção" por Francisco De Gracia}

O trabalho teórico e crítico de De Gracia apresentado no livro Construir en lo construido - la arquitectura como modificación de 1992 tem sido considerado em muitos textos acadêmicos um importante referencial para tratar o tema do antigo-novo e, especialmente, de intervençôes em centros históricos. Com base em Sitte e Rossi, o livro parte do entendimento sobre a arquitetura da cidade como obra de arte, cujo significado se transforma no tempo, criticando tanto a visão modernista de cidade como a visão de "experimentalismos maneiristas" e "modas visuais". Em texto homônimo, apresentado em um evento internacional ${ }^{7}$, em 2013, o autor constrói uma crítica à arquitetura no contexto da globalização, defendendo um "crescimento controlado", com base em aspectos qualitativos, espirituais e culturais e consolida metodologicamente o que chama de "padrôes ou técnicas de relação contextual” para intervir no construído, que nitidamente reconhecemos a partir das análises de "modos de atuação" apresentados em seu livro.

Sobre a relação entre a arquitetura moderna e a cidade histórica, De Gracia (1992, p.111) fala da impossibilidade de a arquitetura moderna dar continuidade às formas da história, por assumir como posicionamentos: a ideia de abstração, apresentada como renovadora do ponto de vista intelectual e ideológico, frente ao figurativo, vista como conservadora; uma concepção anti-tipológica em que a 
"singularidade" do objeto substitui a ideia de "mimese" como neofiliação; e uma manifesta confrontação entre uma "ordem contextual" e uma "ordem do particular”, proclamada em sua realidade autônoma. $\mathrm{O}$ autor ainda aponta a eliminação do método no ensino da arquitetura, apostando na "pura sensibilidade" ou "improvisação criativa”, com prejuízo para a "racionalidade" do projeto - que retoma a partir da referência à tipologia:

A carência de teoria e método, própria do experimentalismo contemporâneo, conduziu a um novo maneirismo que busca soluçôes isoladas, de modo intuitivo - não individualizadas segundo o lugar como condição imprescindível. A dispersão dos recursos maneiristas poderia ser atenuada pelos mass media, mas estes atuam mais como instrumentos homogeneizadores, segundo pautas de colonização cultural, do que como seletores de formas verificadas. (...). Os arquitetos, como agentes fundamentais do processo de gestão formal, têm reunido em sua formação dados heteróclitos de uma experiência aleatória influenciada por modismos visuais. Nada disso favorece a precisão na consecução de formas capazes de satisfazer uma dupla condição de serem ao mesmo tempo particulares e objetivas. A metodologia tipológica, pouco definida instrumentalmente, poderia abrir campo para a superação de fórmulas arbitrárias. (DE GRACIA, 1992, p.62, grifo e tradução da autora).

$\mathrm{O}$ autor defende a necessidade de reconhecer que, no âmbito teórico do patrimônio, as técnicas de in- tervenção possuem um objetivo mais circunscrito, orientadas a uma lógica superior à do próprio objeto que se desenha. Neste sentido, a partir de Francisco Purini, busca distinguir as noçôes de "poética" e de "técnica de invenção":

Evidentemente, as técnicas de invenção nada tem a ver com a poética, que é, por outro lado, o domínio da subjetividade, ainda que seja controlada, e que consiste em um lugar conceitual a partir do qual a experiência pessoal se organiza, em certo sentido e ao mesmo tempo, como memória e como projeto de futuro. De modo contrário, falar de técnicas de invenção significa se referir àqueles procedimentos específicos da arquitetura através dos quais se constitui o pensamento projetual (...). Passado e futuro representam formas de existência do pensamento projetual que deveriam estar unidas pela técnica, para reconstituir um sistema dotado de um grau aceitável de logicidade. (PURINI apud De Gracia, 1992, p.80, tradução da autora).

Segundo De Gracia, toda intervenção será modificadora e deve ter sua validade analisada através de uma crítica metodológica que depende do reconhecimento dos valores atribuídos ao passado e a "arquitetura contextual" é um problema do desenho que deve resolver o conflito entre a individualidade dos objetos e as leis estabelecidas na construção da cidade, buscando a "continuidade", o que não significa homogeneidade, mas possa favorecer a presença de elementos de exceção que atuem como agentes de uma dialética reformadora e criativa. São exemplos citados pelo autor, o Castelo de Abbiategrasso, de 
Giorgio Grassi,1970, a Prefeitura de Götemborg, de Asplund, a ampliação da Whitechapel Art Gallery, por Colquhoun e Miller (1986), o Banco Popular de Verona, de Carlo Scarpa (1973-81) e a Sede dos Arquitetos de Sevilha, de Enrique Perea e Gabriel Cabrero (1977-82).

Em seu livro (1992), De Gracia analisa uma série de exemplos de intervenção, especialmente das décadas de 1970 e 1980 , e o faz de modo categorizado ${ }^{8}$ - passo que reconhecemos como definitivo para a proposição do que chama "teoria geral da modificação". Aponta três opçóes de vínculos determinados por relaçôes compositivas e figurativas: a busca de correspondências métricas, geométricas e de proporção com intenção de conseguir a congruência gestáltica, a reiteraçáo de recursos figurativos ou estilísticos para favorecer a continuidade da imagem e a homologação de opçóes formais mediante o recurso do parentesco tipológico.

Como "padróes de atuaçáo", o autor apresenta: conformaçáo do tecido urbano - recomposição do tecido urbano, interpretado como sistema de volumes construídos através de estratégias de sutura do desagregado; oclusão do espaço urbano - delimitações que criam recintos ou unidades espaciais urbanas mais precisas; continuidade de imagem - relação visual e de congruência das imagens mediante o domínio particular dos recursos plásticos, figurativos ou estilísticos, a partir de princípios gestálticos; recriação de formas tipológicas - coerência formal através de uma controlada redundância, utilizando os tipos, interpretando-os como tendo algum tipo de filiação genética com o lugar; colisão de estruturas formais radicalidade na ação de confrontação formal com o construído, a impossibilidade de continuidade.

Já em seu texto de 2013, percebemos a continuidade da teoria como desdobramento da análise de
1992, pois ele parte dos "padróes de atuação" acima descritos e prescreve: conformaçáo do tecido urbanoprojetar buscando a congruência com o tecido existente; oclusão ou delimitaçâo do espaço urbano - por novos volumes a serviço de uma melhor definição, sobretudo por concavidade, do espaço público; extensão de aspectos figurativos - reforçar a identidade da forma urbana através da analogia figurativa com o construído; reiteração de formas tipológicas - aceitação dos tipos existentes como invariantes temáticos do novo; e ligaçáo de estruturas formais - praticada em qualquer nível, fechamento estrutural por via compositiva gerando congruência formal. Nota-se que De Gracia não prescreve a "colisão de estruturas formais", preferindo apontar a ideia de "ligação de estruturas formais"; embora não declarada no texto, talvez esteja próxima de sua reflexão a respeito das potencialidades da "colagem" a partir de Rowe e Koetter, referidos em 1992 como "modos heterotópicos de formatividade" mais "integradores" dos que "espontâneos".

De Gracia critica procedimentos "de caráter individualista", de "autoexpressáo", que levariam à dificuldade de se desencadear processos significativos comuns, coletivos. Confrontando-se a obras recentes como o edifício Fred \& Ginger de Frank Gehry em Praga (1996) e a Kunsthaus de Peter Cook em Graz (2003), percebemos que sua definição de "arquitetura contextual" praticamente não se altera:

A arquitetura contextual seria aquela que, sem recorrer necessariamente à cópia ou a analogia demasiadamente explícita, estabelece um reconhecível amálgama morfológico com o existente: um tipo de simbiose quando ambas as realidades parecem se reforçar reciprocamente. Dito de outro modo: as partes disfrutam de 
uma interação enriquecedora. Se trataria de algo equivalente à intertextualidade em termos literários, expressão talvez mais precisa. (DE GRACIA, 2013, p.6, tradução da autora)

$\mathrm{O}$ autor destaca que a prática arquitetônica contemporânea "tem direito à sua própria condição histórica", mas vê a necessidade de a inserção "submeter-se às condiçôes específicas e particulares do lugar”, para "concretizar de maneira equilibrada a conjunção morfológica entre o novo e o antigo, mantendo sua identidade respectiva” (2013, p.4).

Notadamente, a visão de De Gracia centra-se no aspecto formal da paisagem. Em suas descriçóes e análises de projeto, o autor pouco comenta sobre aspectos materiais e de significado do ponto de vista dos usos propostos aos espaços. Sua compreensão de intertextualidade é a de influência de um texto sobre outro, gerando, a continuidade de seu significado. $\mathrm{O}$ autor parece refratário, mesmo em se tratando de posturas que interpretam o contexto a partir de discussôes conceituais, a quaisquer abordagens formais de contraste ou de conflito. Seria preciso uma análise de outras de suas publicaçóes para acompanharmos seu pensamento até a formulação de 2013, mas não seria equivocado dizer que seu posicionamento se mantem como um discurso que valoriza a ideia da permanência de aspectos tipológicos e figurativos tanto para o edifício como para os espaços públicos, reafirmando a filiação de seu pensamento a determinados padróes formais ligados à ideia de fechamento da gestalt.

É preciso que coloquemos um distanciamento crítico em relaçáo a alguns dos padrões apontados por De Gracia, fruto de sua reflexão sobre obras dos anos 1970 e 1980 e de uma visão influenciada pelas discussôes do estruturalismo.
Como esclarece Solà-Morales (2003, p.230-236), o movimento neorracionalista pretendeu "teorizar tanto os instrumentos específicos do discurso da arquitetura como os métodos gerais, lógicos e racionais, que poderiam sustentar um exercício prático do trabalho de projetar arquitetura", isto com base na materialidade da arquitetura - a cidade como factum, demonstrando afinidade com o estruturalismo das ciências sociais. O problema da passagem da análise ao projeto foi apontado pelo autor como ambiguidade no movimento: "a ausência de uma definição clara do momento propositivo, projetual, como situação intelectual donde um componente de liberdade, de eleição ou acaso, se introduz sub-repticiamente". Se repensadas, devem ir além do sentido de uma "técnica”, sob o risco de darem continuidade, como Solà-Morales (2006, p.261) chamou a atenção, a uma "verdadeira obsessão": "cultura genuinamente enciclopédica sobre a representação, a comparação dimensional e a consciência estrutural dos problemas da forma”.

O trabalho de De Gracia se insere na discussão "culturalista" com traços de "historicismo", de base formal e estruturalista e que sua proposta metodológica se fixa na análise e identificação das estruturas do local (ou da referência à estrutura da cidade tradicional) em especial, nos centros históricos - prescrevendo a manutenção de padróes tipológicos e figurativos. A noção de "técnica inventiva" se aproximaria da ideia de mimese como metalinguagem - operação em que a arquitetura fala de si mesma. Por outro lado, quando apresenta o contextual para além da "cópia" ou da "analogia demasiadamente explícita" com a ideia de "ligação de estruturas formais" abre a possibilidade da inserção de novas formas - o que pode ser aproximada da ideia de "colagem"; em seu pensamento, restrita ao princípio gestáltico de fechamento ou à 
ideia de congruência entre as partes.

Não há como negar a contribuição de sua visão sobre o "contextual" especialmente no que se refere ao desejo de valorizar o pré-existente e a paisagem como "amálgama”, em que o novo e o antigo guardam uma relação morfológica como "todo".

Vemos com grande interesse o modo como de De Gracia se aproxima da ideia de "genius loci", reconhecendo que toda intervençáo implica em transformação do lugar e dos seus significados, "arquitetura como modificação", inclusive do próprio "genius loci”, o que se aproximaria do que entendemos como possibilidade de reinvenção do lugar, mas vale pensar o quanto a "poética" ou a "liberdade" do artista como operação também contextual - pode ir além de procedimentos formais e de desenho.

\subsection{Arquitetura e "contextualizaçáo ativa" por Giovanni Carbonara}

No livro Architettura d'oggi e restauro - um confronto antico-nuovo de 2011, Giovanni Carbonara defende que para enfrentar a questão do antigo-novo é necessária uma abordagem que reúna conhecimento conceitual e crítico sobre as práticas contemporâneas em arquitetura, teoria do restauro e até filosofia, abrangendo conceitos como memória, esquecimento, história, técnica, tradição e modernidade. $\mathrm{O}$ autor fala da necessidade de critérios "categoriais" que permitam enquadrar, ler e valorar diferentes opçóes e casos, que abrangem diversos âmbitos de interesse: a arquitetura e suas variadas derivaçóes, a inserção contemporânea sobre a pré-existência e a conservação e restauração em todos os níveis incluindo o paisagístico e urbanístico.
Como dito, Carbonara monta o problema da intervenção antigo-novo a partir da oposição entre uma arquitetura que retoma os valores de uma modernidade vanguardista e revolucionária e de outro, de uma pós-modernidade regressiva. Defende uma "terceira via": "não anti-histórica como a cópia, nem a-histórica como a arquitetura gestual, mas historicamente consciente, verdadeiramente 'crítica e criativa'” (2011, p.47, tradução da autora).

O autor parte da reflexão de Benedetti de 2004, para quem a "contextualização ativa" não é liberdade total, mas uma abordagem que, sem renunciar a um "sentir" contemporâneo, se propõe a constituir "reverberação e consonância" em relação ao contexto onde se insere. A intervenção se apresenta como face contemporânea, mas "não pretende com a sua figura contrastar ou conturbar o equilíbrio figurativo do conjunto", ela reconhece as "razóes de longa duração - as constantes da tradição e da estabilidade tipológica, das normas processuais da razão":

A tarefa de nosso tempo não é copiar ou refazer o verso, a modalidade estilística do passado, mas tomar suas impressóes e reinterpretar o caráter na chave da linguagem de hoje, levar a uma nova síntese a sugestão suscitada pela estrutura figurativa da pré-existência. (Benedetti apud CARBONARA, 2011, p.42, tradução da autora).

Carbonara (2011, p.47) apresenta este posicionamento por distinção ao de Bardeschi de 2004 que qualifica como predileção pela natureza própria da linguagem do novo, para quem, no caso do próprio restauro, não se justifica o sacrifício de elementos, recomenda-se a absoluta conservação. Nesta visão, o novo pode ter plena autonomia e clara legibilidade 
no contexto como um produto figurativo e material inovador.

Carbonara faz a ressalva de que "o contraste com o antigo, desde que bem estudado, é preferível à imitação ou réplica linguística” (2011, p. 4-6), pois a inserção do elemento novo deve ser "atentamente motivada e avaliada / valorizada em sua modalidade expressiva”. Fala inclusive, e de modo positivo, de uma "modernidade dialética" a partir de Portoghesi, reconhecida em Louis Kahn, Frank Lloyd Wright e Mário Botta.

A partir de Catucci, Carbonara entende a arquitetura como "arte condicionada", a possibilidade de "boa convivência” formal, trazendo uma definição de arte, diferente da liberdade absoluta, com base em Purini (2006):

A obra de arte é um sistema em contínua transformação (...) construir na cidade é um ato crítico que de qualquer modo refunda a realidade sobre a qual se age; no momento em que ela é modificada pela intervenção arquitetônica, o novo se contamina com o existente e este se torna diferente em contato com o novo (...) gerando uma terceira entidade. (Purini apud CARBONARA, 2011, p.37, tradução da autora)

Vemos com interesse quando Carbonara, acompanhando Purini, reconhece três fases que envolvem o projetar no antigo-novo: o reconhecimento do existente, a apropriaçáo do mesmo por um processo empático e a produção da diferença. Para tal criação, diz Carbonara, não se deve pensar de modo historicista, ou seja, a história não deve ser vista como uma sequência de encadeamentos e o significado de um monumento não deve ser atribuído a partir de sua "aparência da história", mas sim de sua "presença material”.

A ideia de apropriação por um "processo empático" nos leva a pensar, com base na fenomenologia, na possibilidade de "ressonância" do passado a partir do "contato" do arquiteto com "coisa mesma" que é o bem, não por reconhecimento "estilístico", mas por ser tocado por valores arquitetônicos - formais, espaciais, tectônicos e materiais, e proposição de vivências (na relação ou não com o uso) - capazes de incitar, provocar, levar à produção do novo como diferença, mobilizando, ao mesmo tempo, memória e invenção. Retomando suas palavras:

Somente o uso desta memória pode levar à superação da tradicional contraposição antigo-novo, entre tutela e inovaçáo, conservaçáo e projeto, por reivindicar uma 'arquitetura da duração' que corresponde a uma 'tradição outra da modernidade' na qual a linguagem inovadora e a linguagem consolidada da história venham a se misturar, como se entrando em ressonância, tornandose complementares. (CARBONARA, 2001, p.45, tradução da autora)

Ao enfatizar a questão da linguagem, o autor trata da possibilidade da "analogia" como interpretou Solà-Morales (1985): um procedimento com "declinações pessoais", distinto da imitação estilística; descreve-a como "adição crítica", "dosagem controlada lidando entre semelhança e diferença" e a "interpretação dos traços dominantes do edifício antigo com o propósito de fazer eco" (CARBONARA, 2001, p.45), "moderna, mas não indiscriminadamente criativa", visando conservar a "unidade arquitetônica do artefato" - no que reconhecemos a ascendência de Brandi em seu pensamento. 
Vale pontuarmos que a analogia é reconhecida em Solà-Morales (2006, p.262) como a convivência entre diferença e similaridade, operação estética que é "proposta livre, arbitrária e imaginativa pela qual se procura não só reconhecer as estruturas significativas do material histórico existente, como também usá-las como marcos analógicos para a nova construção”. É o que o autor percebe na visão de Rossi, que trabalha com os tipos de modo fragmentário e associação livre - em suas próprias palavras, como uma "meditação interior", em que a subjetividade e a imaginação estão implicadas. Ou na "analogia" de Carlo Scarpa, em que elementos fragmentários permitem associaçôes por conotarem, não denotarem, relaçóes entre o novo e o antigo. Reconhece-se, portanto, que a operação analógica, engendrada a partir da seletividade e da liberdade de associação próprias à memória, pode afirmar-se como ação poética sugerindo tanto a continuidade como a descontinuidade - ressonância eco, mas também apagamento, fragmentação.

Carbonara posiciona-se claramente contra intervençôes delirantes e aplicaçôes passíveis de crítica (as mais radicalmente "desconstrutivistas") por considerarem que a obra de arte está sujeita à interpretação de seu tempo atual, considerando-a apenas um pretexto para uma nova germinaçáo.

Como notou Umberto Eco, no caso da música, uma dissonância perturbadora inserida no contexto apropriado pode provocar efeitos de tensão e espera que contribuem para a beleza global da ópera (o 'diabolous' na música). Não há dúvida que a história da arquitetura foi nutrida de episódios similares (basta pensar em Bramante ou Borromini). Mas para o propósito da discussão sobre a sobreposição de linguagens/línguas, intervir inserindo um 'diabolous' arquitetônico no texto de outrem, seria como conscientemente inserir dissonância no interior de uma sinfonia musical de grande importância, alterando o produto de um outro autor. (RACHELI apud CARBONARA, 2011, p.50, tradução da autora)

No capítulo em que define "categorias e exemplos", reunindo açóes de preservação tanto de restauro como de inserçôes de novas arquiteturas em sítios de valor patrimonial, Carbonara afirma reconhecer diferentes atitudes, todas potencialmente legítimas, dependendo do perfil estritamente crítico, do julgamento que rege o tipo de intervenção alcançado em relação às qualidades históricas e artísticas reconhecidas a partir das pré-existências individuais (CARBONARA, 2011, p. 111). São elas: 1. Autonomia / Dissonância: Contraste / Oposição; Destaque / Indiferença; Distinção / Não assonância; 2. Assimilaçáo / Consonância: Mimese / Ripristino; Analogia / "Tradição"; Restituição tipológica; 3. Dialética / Reintegraçáo da Imagem: Dialética crítico-criativa / reinterpretação; Filologia "projetual" / coextensão; Reintegração da imagem / acompanhamento conservativo; 4. Náo intervençáo direta; 5. Conservaçáo imaterial; 6. Intervençáo Ambiental.

Dialética / Reintegração da Imagem é apresentada como tema mais afeito às posturas das intervençóes de restauro quando o novo é posto "à serviço do antigo"; enquanto Autonomia / Dissonância e Assimilação / Consonância seriam aquelas que mais se aproximam da discussão de arquiteturas novas, inseridas como diferença, em contextos pré-existentes. Podemos arriscar dizer que as subcategorias extremas destes últimos parecem distantes do que o próprio autor colocou como possibilidade de uma "terceira via". 
Na situação de Autonomia / Dissonância (Carbonara, p. 111-114), o extremo é o "Contraste como oposiçáo", que o autor coloca como "discordância desejada, arquitetônica, linguística ou espacial, em alguns casos de abordagem 'violenta', que de certo modo remonta à experiência artística dadaísta ou expressionista" - a exemplo da Piazza di Toscano em Cosenza, de Marcello Guido (2000-2002). A ideia de "Destaque / indiferença", reconhecida por exemplo do Museu de Moritzburg em Halle, de Nieto Sobejano Arquitectos (2005-2008), é a "abordagem que se apresenta como sobreposição forçada, opressiva, ou se se prefere, convivência parasitária", enquanto que a "Distinçáo / náo assonância" seria uma "procurada antítese antigo-novo, em autenticidade expressiva e autonomia física e linguística (...) sofisticada diversidade", como observada no projeto de Peter Zumthor para o Abrigo das Ruinas em Coira (1986).

Embora reconheça as possibilidades estéticas da dissonância, especialmente comparadas à ideia de colagem na arte, Carbonara posiciona-se por uma visão crítica em que "o critério de juízo não seja fundado unicamente pela exigência e especulação do contemporâneo" (2011, p. 104) - como exemplo negativo, cita o projeto de intervenção do Caixa Fórum (2002) de Herzog e De Meuron, em Barcelona e do mesmo grupo, valoriza a intervenção no Tate Modern em Londres (2000), destacada como exemplo de muito pensamento e vontade ética.

Concordamos com o autor que a visão especulativa da cidade deve ser afastada, mas vale discutir que a ideia de colagem, como poética heterotópica e sem unidade integradora, pode ser fruto de uma visáo conceitual do trabalho, a exemplo da proposição da fragmentação como imagem das diferenças que já constituem determinada paisagem, buscando expor o encontro de diferentes vozes como complexidade inerente.

Na situação de Assimilação / Consonância (2011, p.118), o extremo é "Mimese/ Ripristino", que seria a abordagem guiada por "vontade imitativa e regressiva de continuação linguística", desde a reconstrução 'filológica' de partes selecionadas ao edifício inteiro. Em desdobramento, estaria "Analogia / “Tradição" que define como "recuperação dos princípios compositivos e da técnica", a exemplo do projeto de Aldo Rossi para o Palácio do Congresso em Milão, 1989. O autor refere-se também à "Restituiçáo tipológica" que "ocorre nos termos de recuperação do arquétipo e de uma retomada linguística, há uma evidente componente teórica mais estruturalista que historicista", como a intervenção de Giorgio Grassi no Teatro de Sagunto (1985-1993), que reconhece como jogo combinatório de elementos para fazer da ruína um edifício. Carbonara parece nestas categorizações manter-se mais próximo do pensamento estruturalista.

Vale lembrarmos, como já referimos, que Carbonara reconhece os contornos dados ao conceito de analogia por Solà-Morales, de modo mais aberto, reconhecendo as "declinaçôes" pessoais dos arquitetos. $\mathrm{Na}$ mesma linha, podemos citar a já referida compreensão de Rafael Moneo sobre o tipo e seu uso criativo pelos arquitetos, a exemplo de articulaçôes sutis de fragmentos de estruturas formais do passado.

Ao tratar do tema do antigo-novo, partindo destas duas categorias de Carbonara, Beatriz Kühl (2008) aproxima a "diferenciação em dissonância" da abordagem da "conservação integral" e a "diferenciação em consonância" do posicionamento "crítico-conservativo”. A autora recorre à metáfora da música: na consonância pretende-se conjugar notas diversas num acorde harmônico sem, porém, trabalhar por 
simples imitação; na dissonância cabe ao arquiteto interpretar como pode contribuir para valorizar o conjunto, explorando a polifonia (mas evitando a cacofonia - a ostentação de sua presença).

Carbonara entende a relação "antigo-novo" de modo mais aberto do que outros autores (inclusive De Gracia; como possibilidade da diferença - não só a consonância é válida, mas também a dissonância, desde que os projetos não cedam à especulação ou não sejam "diabolous" a comprometer o valor artístico da pré-existência.

Somamos à ideia do autor, a possibilidade de que a dissonância seja constituída a partir de posicionamentos interpretativos sobre o pré-existente, construídos em bases conceituais, lembrando Tschumi quando a ideia de "conflito" pode emergir como um posicionamento ideológico.

Carbonara, em sua excessiva taxonomia, indica possibilidades desde a consonância e a dissonância, mas devemos considerar que, ao analisarmos as intervençôes, é possível se reconhecer em uma única obra aspectos consonantes e dissonantes, uma vez que não só linguagem, forma e espacialidade devem ser considerados, mas também aspectos materiais e tectônicos, além da proposta de usos e de apropriação dos espaços. A análise de cada obra em seus múltiplos aspectos, levando em consideração também a poética dos arquitetos e seu modo de interpretação do lugar nos parecem mais relevantes para o reconhecimento do valor das intervençóes, buscando evitar juízos a priori.

O que o autor nomeou "terceira via" hoje deve ser reconhecido como a possibilidade de múltiplas vias, diferentes atitudes que trabalham com a ideia de "cultura arquitetônica", entre a tradição e a inovação, convocando a memória como possibilidade de in- venção a partir também dos meios contemporâneos.

\section{A relaçáo antigo-novo como possibilidade inventiva entre memória e inovaçáo}

Diante de projetos contemporâneos que já partem da crítica que foi feita tanto ao pós-modernismo de citação historicista como à retórica futurista-tecnológica High Tech, as abordagens sugerem uma visão crítica do tema do contextual para além de "enquadramentos" absolutos e da ideia de um único método que possa validar as açóes antigo-novo.

Ou seja, para a crítica das obras contemporâneas devem ser considerados possíveis deslocamentos inventivos entre a memória e a inovação, não só considerando as bases do formalismo visual e da Gestalt, mas também da abordagem dada à experiência a partir do corpo pela fenomenologia, o reconhecimento das questôes da linguagem a partir do estruturalismo e do pós-estruturalismo e dimensões discursivas como partícipes do campo dos significados (a pré-existência como um objeto-discurso).

Apontamos três exemplos contemporâneos ${ }^{9}$ que abordam a convivência de múltiplas temporalidades de diferentes modos mobilizando inventivamente $\mathrm{e}$ artisticamente, ao mesmo tempo, memória e inovação, que vemos como poéticas que, por sua relação com o contexto, criam "lugares complexos". O projeto de Norman Foster para a cúpula do Reichstag em Berlim (1995-99), restituindo ao todo sua imagem e estrutura formal, mas reinterpretando o significado político e democrático do edifício a partir de uma cúpula que se torna mirante (da cidade e da sala de decisóes) totalmente transparente e acessível ao caminhar - somente possível pela exploração de novas tecnologias e materiais (Figura 1 ). $\mathrm{O}$ projeto 
de Peter Zumthor para o Museu Kolumba em Colônia (2001-2009), que explora os sentidos da ruína e do sagrado, construindo a partir de seus fragmentos uma experiência do sublime, fenomenologicamente, uma imagem poética que explora a relação entre os materiais e efeitos da luz (Figura 2). E o projeto da Bernard Tschumi para o Museu da Acrópole, em Atenas (2001-2009), em que se reconhece a interpretação do contexto como superposiçáo de camadas a serem experienciadas pelo visitante como sequencia espacial, eventos em sucessão e em relação às próprias peças expostas, culminando na relação com o próprio Parthenon, construindo não só uma relação visual, mas também em sentido conceitual e crítico sobre o tema da repatriação das obras (ao se destacar a ausência das peças que estão no Museu de Londres e o próprio papel dos museus, expondo a preservação como a substituição por réplicas no local original (Figura 3).

Devemos nos prevenir dos "rótulos" - "arquitetos artistas", "arquitetos do star system", "desconstrutivis- tas" ou "high tech", para ir ao encontro de cada obra e investigarmos a possibilidade de seu reconhecimento como um modo de relaçáo contextual, como poética. Os posicionamentos dos arquitetos devem ser reconhecidos como caminhos do pensamento que muitas vezes se apresentam de modo diferencial quando analisamos as obras de um mesmo autor ao longo do tempo.

Não há oposição entre artístico e contextual, há diferentes modos de pensar a produção de "lugar" na contemporaneidade na relação com a permanência e a produção, e entender a experiência estética da paisagem como parte de um processo em que a produção de significados está em questão. De modo bastante amplo e multiplicado, podem nos levar a qualidades estéticas distintas e válidas se justificadas com base em valores materiais e imateriais da paisagem e em que visão de cidade, como obra de arte, está se propondo.

Devemos reconhecer a memória como um processo

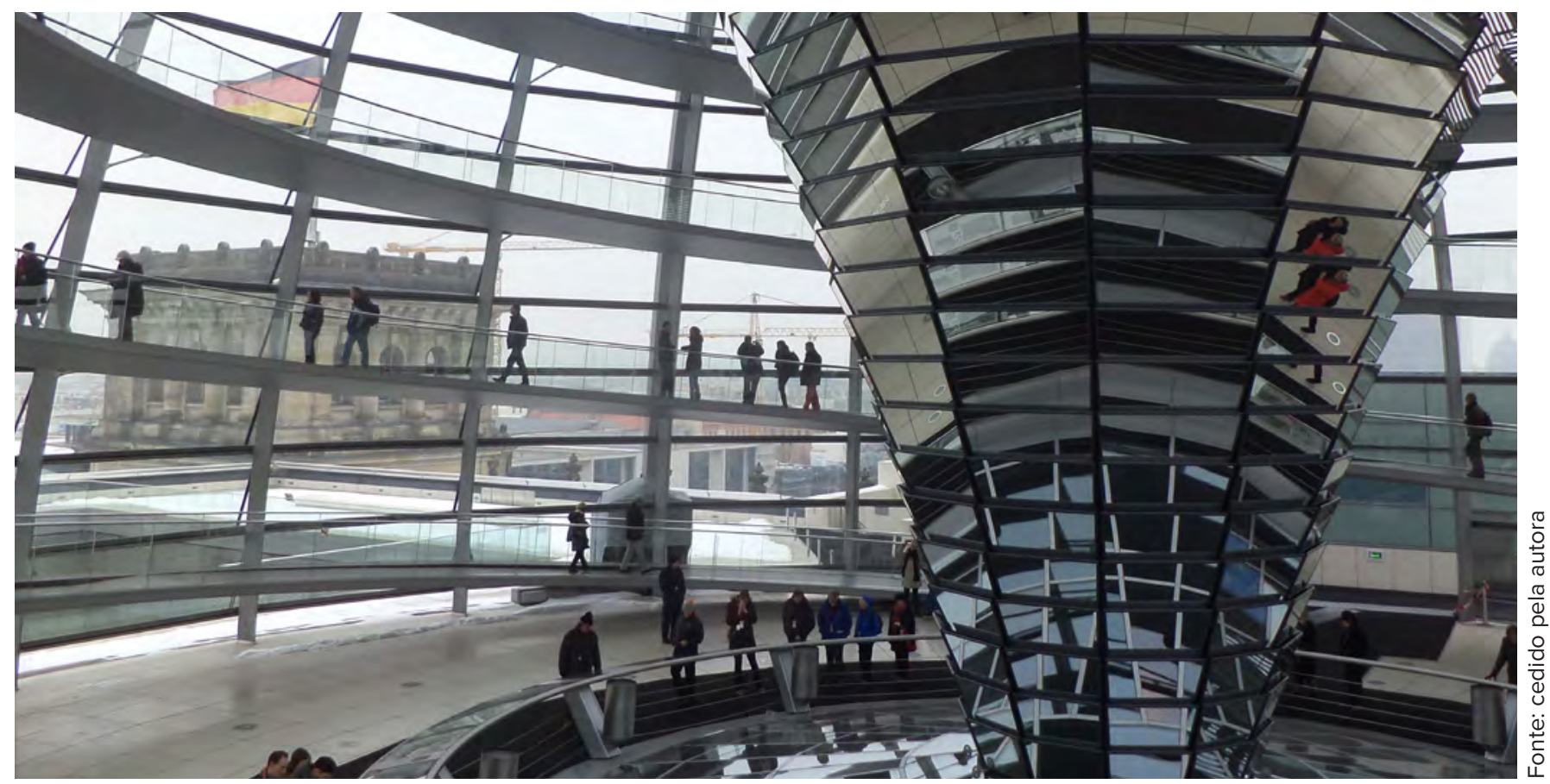

Figura 1: Norman Foster, Cúpula do Reichstag em Berlim (1995 - 99).

Revista online do Departamento de Arquitetura e Urbanismo da Pontifícia Universidade Católica -

Puc-Rio - Rio de Janeiro Brasil

Ano I- N ${ }^{\circ}$ I - ISSN 2446-7340 


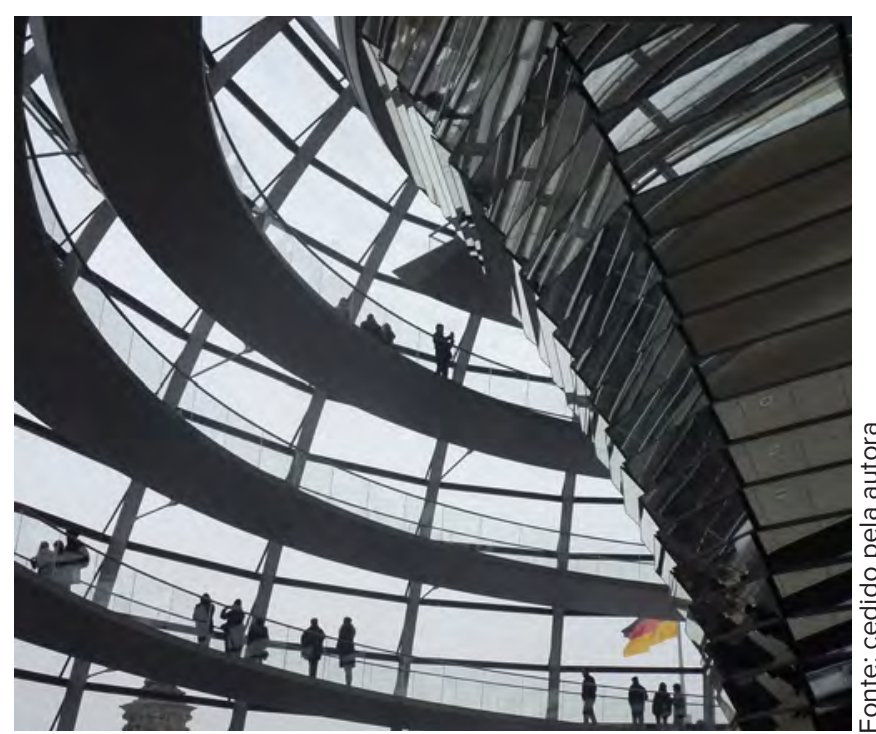

Figura 2: Norman Foster, Cúpula do Reichstag em Berlim (1995 - 99).

intempestivo, seletivo e fragmentário, mas também intuitivo capaz de construir associaçóes no campo da imaginação. A criaçáo pode advir da convicção da potência de "reinvenção do lugar" para construir o próprio sentido de cultura como um processo vivo.

A abordagem "caso a caso" segue sendo a opção mais pertinente considerando-se a diversidade de situaçóes encontradas - não só das pré-existências em si - mas de sua "ambiência" ou da paisagem diferencial onde se inserem.

Uma paisagem cultural deve ser cuidadosamente analisada pelo arquiteto na construção da "problemática" em questáo considerando seus muitos aspectos - não só morfológicos e visuais, climáticos e ambientais, mas especialmente sociais no que se refere aos usos e significados. Não há um único método ou "resposta" ao problema levantado, especialmente considerando-se que o conjunto novo e antigo é capaz de evocar novos sentidos, sempre abertos.

Se a arte pede um olhar livre, ele é entrelaçado, de modo complexo, ao mundo e seu campo de significados no presente. Não guardemos a nostalgia de



Figura 3: Peter Zumthor, Museu Kolumba em Colônia (2001-2009).

um tempo perdido, seja do passado seja do futuro como tratou Rem Koolhaas, mas a ideia de que estamos transitando na contemporaneidade "entre" estas duas bases, como condição mesmo de pensar a cultura e nossa relação com o tempo.

O tempo da arte é o tempo que conduz à experiência capaz de nos transformar; a arte possui esta intensidade. Em sua relação com o tempo, sempre será o tempo que, de algum modo, subverte a experiência naturalizada que dele temos. Diante dos desafios que se impóem, a arte das intervençôes deve trabalhar para produzir novos significados como ressonâncias coletivas e individuais do passado no presente, e do presente como aquele que constrói diferentes olhares para o passado. 


\section{Notas de fim}

1. O livro da autora, publicado pela Editora FGV em 2014, é fruto da tese de doutorado "Poéticas da complexidade - o lugar contemporâneo e os limites da arquitetura entre arte e paisagem" (Departamento de História, PUC-Rio, 2010, orientação de João Masao Kamita e Cecilia Cotrim).

2. Sobre nossa reflexão sobre valor artístico contemporâneo na relação com lugares de memória, ver ZONNO, F.V. "Intervençôes artísticas e arquitetônicas em lugares de memória - modos de interpretação do lugar”. In: TREVISAN e NOBREGA (Org.). Projeto e Patrimônio - reflexóes e aplicaçóes. Rio de Janeiro: Rio Books, 2016.

3. Nossa pesquisa "Entre Arte, Arquitetura e Paisagem - teoria e crítica da complexidade contemporânea”, no âmbito do Grupo Pensamento, História e Crítica do PROARQ-FAU/UFRJ, tem se dedicado ao tema da memória, com apoio de bolsistas CNPq-UFRJ

4. Francisco De Gracia é professor de "Composição arquitetônica” na Escuela Técnica Superior de Arquitectura de Madrid (ETSAM). Como pesquisador, participa do Grupo de Investigación Paisaje Cultural (GIPC) de la Universidad Politécnica de Madrid (UPM). Como arquiteto realizou obras de restauração e reabilitação de edifícios históricos. É autor de Construir en lo construido (1992), Entre el paisaje y la arquitectura (2009) e Pensar / componer / construir (2012).

5. Giovanni Carbonara é arquiteto italiano, historiador de arquitetura e teórico do Restauro, representante da Scuola Romana. É autor de vários livros dentre eles: Avvicinamento al restauro (1997) e Restauro Architettonico: principi e metodo (2012).

6. Gustavo Rocha-Peixoto (2013) analisa 3 modos de articulação do pensamento historiográfico - historicista, histórico-modernista e culturalista - como paradigmas ou epistemes, que náo constituem etapas sucessivas, mas se alternam na "cena aberta" do campo disciplinar da arquitetura. $\mathrm{O}$ modo culturalista reco- nhece a escrita da história como uma narrativa ficcional do tempo, que envolve a subjetividade do historiador como intenção, depende da intenção do autor, ou melhor, da seleção de documentos e da construção de uma "intriga" que sustenta.

7. Encuentro Internacional de Arquitectura Contemporánea en Ciudades Históricas, realizado em Sevilha em setembro de 2013, organizado pela Prefeitura de Sevilha, com a colaboração do Mi

8. Em uma postura tipicamente historicista, De Gracia em 1992 categoriza as obras analisadas como "atitudes frente ao contexto": arquitetura descontextualizada, arquitetura de contraste; arquitetura historicista; arquitetura folclórica; arquitetura de base tipológica; arquitetura do fragmento; e por fim trata a "arquitetura contextual" como um grupo do qual podem participar exemplos de outras categorias desde que comprometidas com o "princípio diacrónico da forma da cidade". nistério de Educação, Cultura e Esportes da Espanha, Centro de Patrimônio Mundial da UNESCO, ICOMOS e a Organização de Cidades Patrimônio Mundial.

9. Para análise destas e outras obras contemporâneas ver artigos: ZONNO, F.V. "Intervençóes artísticas e arquitetônicas em lugares de memória”. In: TREVISAN e NÓBREGA. Projeto e patrimônio - reflexões e aplicações. Rio de Janeiro: Rio Books, 2017, p.36-63 


\section{Referências Bibliográficas:}

CARBONARA, G. Architettura d'oggi e restauro - um confronto antico-nuovo. Torino: UTET Scienze e Tecniche, 2011.

DE GRACIA, F. Construir en lo construido - la arquitectura como modificación. Madrid: Editorial Nerea, 1992.

"Construir en lo construido"(2013).

Encuentro Internacional de Arquitectura Contemporánea en Ciudades Históricas. Disponível em: <http:// unesco.urbanismos evilla.org/unesco/sites/default/ files/02.FranciscoDeGraciaponencia.pdf $>$. Acesso: mar, 2016.

DUARTE, F. Crise das Matrizes espaciais. São Paulo: Perspectiva, FAPESP, 2002.

KOOLHAAS, R.; MAU, B. S, $M, L, X L$. New York: Monaceli Press, 1995.

KÜHL, B. Preservação do patrimônio arquitetônico da Industrialização: problemas teóricos de restauro. Cotia, SP: Ateliê Editorial, 2008.

MONEO, R. On Typology. Oppositions, n.13, 1978.

NORBERG-SCHULZ, C. "O fenômeno do lugar" (1976) In: NESBITT, K. Uma nova agenda para a arquitetura. São Paulo: Cosac Naify, 2005, p.443-461.

ROCHA-PEIXOTO, G. A estratégia da aranha - ou da possibilidade do ensino metahistórico em arquitetura. Rio de Janeiro: Rio Books, 2013.

ROSSI, A. A arquitetura da cidade (1966). 2.ed. São Paulo: Martins Fontes, 2001.

ROWE E KOETTER. "Cidade colagem" (1975). In: NESBITT, K. Uma nova agenda para a arquitetura - Antologia teórica 1965-95. São Paulo: Cosac, 2006. p.293322.

SOLÀ-MORALES, I. Diferencias - Topografías de la Arquitectura Contemporánea. Barcelona: Gustavo Gili, 2003.

. "Do contraste à analogia - novos desdobramentos do conceito de intervenção arquitetônica” (1985). In: NESBITT, K. Uma nova agenda para a arquitetura . Antologia teórica 1965-
95. São Paulo: Cosac, 2006a. p.252-264. Inscripciones. Barcelona: Gustavo Gili, 2003. Intervenciones. Barcelona: Gustavo

Gili, 2006b

TSCHUMI, B. Event Cities 3 - Concept, Context, Content. Cambridge: MIT Press, 2004.

zoli, 2012.

Red is not a color. New York: Riz-

ZONNO, F.V. "A interpretação do contexto na obra "de limite" de Bernard Tschumi", Revista ARQ URB, 2016.

"Intervenções artísticas e arquitetônicas em lugares de memória". In: TREVISAN e NÓBREGA. Projeto e patrimônio - reflexóes e aplicaçôes. Rio de Janeiro: Rio Books, 2017, p.36-63.

. Lugares complexos, poéticas da complexidade. Rio de Janeiro: FGV, 2014. 